\title{
Dental care for the patient with a cleft lip and palate. Part 1: From birth to the mixed dentition stage
}

\author{
C. J. Rivkin, ${ }^{1}$ O. Keith, ${ }^{2}$ P. J. M. Crawford, ${ }^{3}$ and I. S. Hathorn, 4
}

\section{This is the first of two articles looking at dental care for the patient with a cleft lip and palate. Part 1 looks at the needs of the child with a cleft lip and palate from birth through to the mixed dentition stage.}

\begin{abstract}
Cleft lip and palate is one of the commonest congenital abnormalities. Around 1 in every 700 live births in the UK has a cleft of the lip and/or palate. ${ }^{1,2}$ The type of cleft can range from a simple incomplete cleft of the soft palate, which is not clinically obvious and may be undiagnosed in the early days, to a bilateral complete cleft involving both the soft and hard palate, alveolus and lip (Fig. 1).

Management of the patient with a cleft is best carried out by a multi-disciplinary team of healthcare professionals who undertake the cleft care from birth through to adulthood. ${ }^{3}$ Specialities represented on the cleft team in the UK vary from region to region but the core members of the team are the surgeon, orthodontist, speech and language therapist, and ENT specialist. The Royal College of Surgeons Steering Group on Cleft Lip and Palate recommends that the care of chil-
\end{abstract}

\footnotetext{
$1^{*}$ Senior Community Dental Officer, Honorary Lecturer in Paediatric Dentistry, Specialist in Paediatric Dentistry, Community Unit, Division of Child Dental Health, Bristol Dental Hospital, Lower Maudlin Street, Bristol BS1 $2 L Y^{2}$ Consultant Orthodontist, Maxillofacial Unit, Derbyshire Royal Infirmary, London Road, Derby DE1 2QY ${ }^{3}$ Consultant Senior Lecturer in Paediatric Dentistry, Division of Child Dental Health, Bristol Dental Hospital, Lower Maudlin Street, Bristol BS1 2LY ${ }^{4}$ Consultant Orthodontist, Division of Child Dental Health, Bristol Dental Hospital, Lower Maudlin Street, Bristol BS1 2LY

${ }^{*}$ Correspondence to: Dental Department, Newton Heath Health Centre, 2 Old Church Street, Newton Heath, Manchester M40 2JF REFEREED PAPER

Received 17.03.98; accepted 04.06.99

(c) British Dental Journal 2000; 188: 78-83
}

dren with clefts should be carried out by a team whose members are able to provide a comprehensive service including: dental care, audiology, specialised counselling and clinical genetics. ${ }^{4}$ The Clinical Standards Advisory Group Report on Cleft Lip and/or Palate stresses the importance of team work between all the specialities. ${ }^{5}$

While the child with a cleft lip and palate should be treated as a 'normal' patient whenever possible for regular dental care, there are specific needs with regard to oral health which can be identified at different stages of dental development through to the adult years. The dentist providing regular dental care might be a general dental practitioner, community dentist or hospital dentist. The aim of this article is to discuss the

\section{In brief}

- The dentist has an essential role in giving early preventive advice for the young child with a cleft lip and palate

- The parents are helped to focus on the importance of good oral health for their child

- Advice on weaning practices and dentally-safe foods and drinks is important

- Particular attention should be given to toothbrushing in the cleft region

- Reassurance regarding the variability of dental development in the cleft area is helpful.

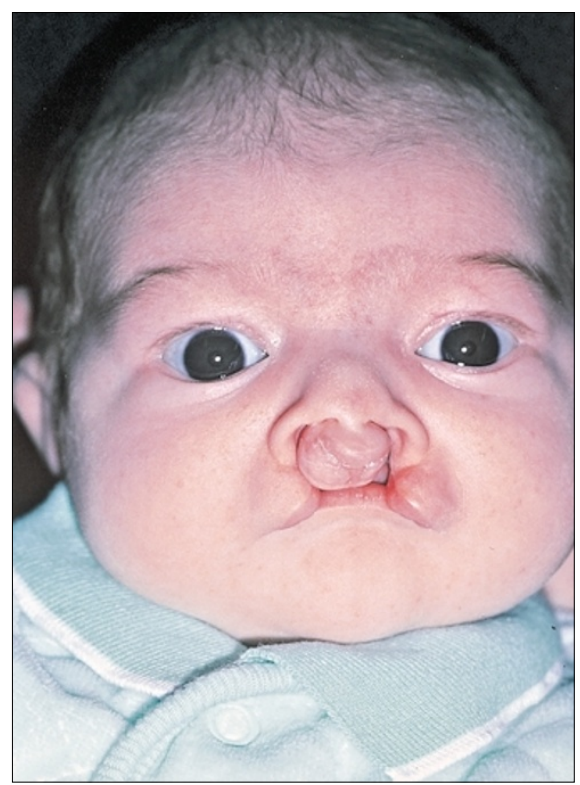

Fig. 1 A 2-month-old child with a complete bilateral cleft lip and palate

role of the dentist in the dental management of the patient with a cleft lip and palate.

The baby with a cleft lip and palate and the pre-mixed dentition years Within the first few days after the birth, parents of babies born with a cleft lip and palate will receive advice in hospital from the surgeon and orthodontist on the immediate and long-term management of their child. This will often be supplemented by written information on the condition itself, and related aspects including oral health and dental care. The orthodontist is usually the first dental specialist whom the family will encounter. The cleft and cranio-facial unit may have a cleft co-ordinator or other named person, such as a clinical nursing specialist, to give support to the family and advice on feeding. The health visitor and general medical practitioner 


\section{PRACTICE cleft lip and palate}

\section{Fig. 2 High caries rate in a child with a bilateral cleft lip and palate. First dental visit at the age of 7 years}
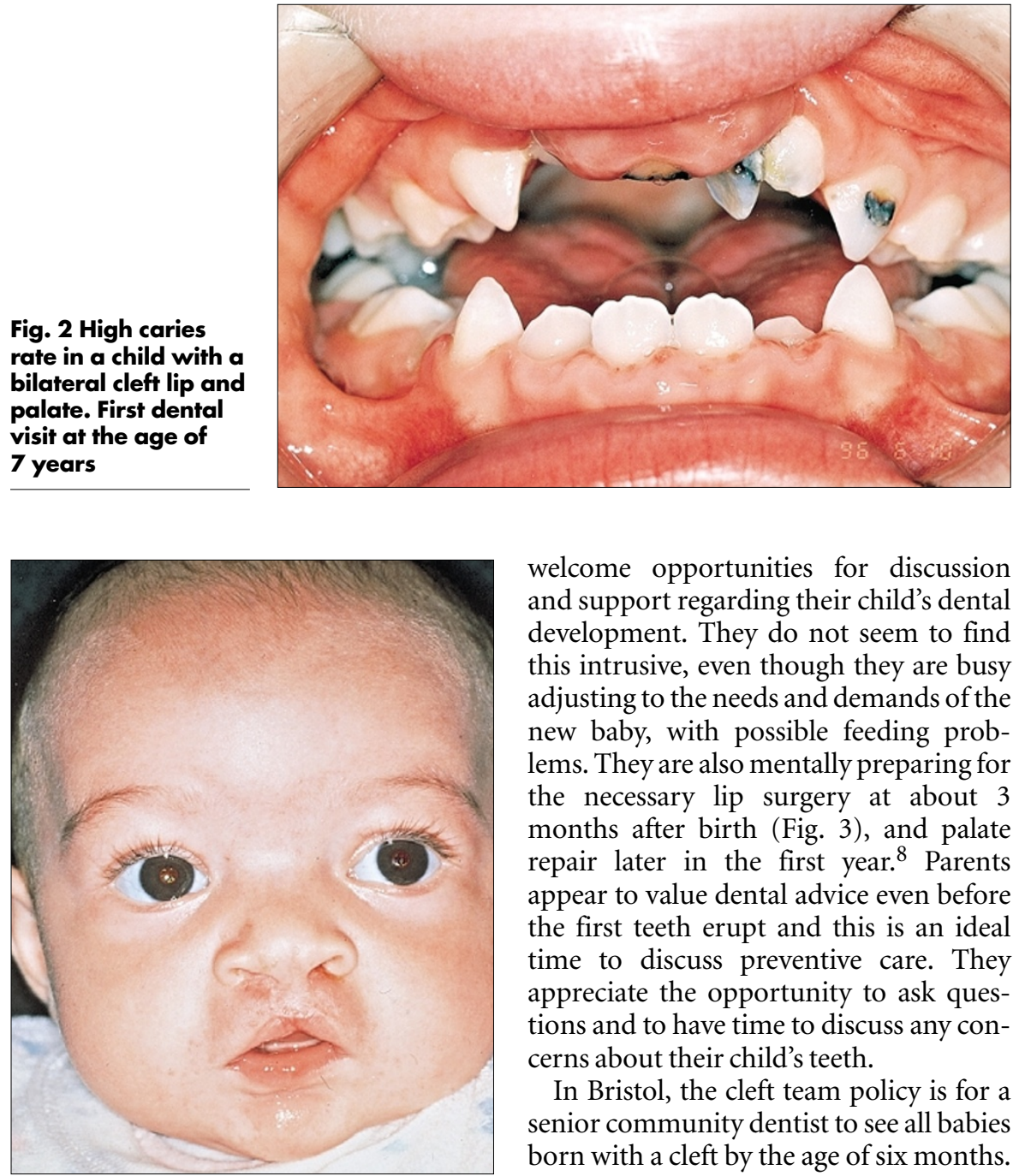

Fig. 3 The child in Fig. 1 shown at age 6 months. Bilateral cleft lip and palate following lip repair

also have their traditional roles to play in post-natal support and ongoing care.

There may be a hiatus with regard to dental care between this early stage and the first dental check-up, especially if the family general dental practitioner does not register children below a certain age, (sometimes 2-2fi years). By this time caries may already have developed in the primary dentition. ${ }^{6,7}$ In some cases there is not a family dentist and the child then 'slips through the net' for regular dental care (Fig. 2).

Parents of babies with a cleft appear to welcome opportunities for discussion and support regarding their child's dental development. They do not seem to find this intrusive, even though they are busy adjusting to the needs and demands of the new baby, with possible feeding problems. They are also mentally preparing for the necessary lip surgery at about 3 months after birth (Fig. 3), and palate repair later in the first year. ${ }^{8}$ Parents appear to value dental advice even before the first teeth erupt and this is an ideal time to discuss preventive care. They appreciate the opportunity to ask questions and to have time to discuss any concerns about their child's teeth.

In Bristol, the cleft team policy is for a senior community dentist to see all babies born with a cleft by the age of six months. This is arranged by the orthodontic team involved with cleft care. Reassurance,
Fig. 4 An 8-year-old child with a left unilateral cleft lip and palate. Early extraction of the upper right primary second molar has resulted in space loss information, preventive advice and acclimatisation are the important aspects of these early visits. Parents can be particularly anxious about teething and what the teeth might look like when they eventually erupt. Understandably, they often focus on the anticipated future appearance of their child's teeth. It is important that the parents understand the value of good dental health from the outset and are helped to focus instead on this aspect of the oral development. Establishing the correct dental habits from an early age will help to ensure the health of the primary and permanent dentition.

Pain, sepsis, or the need for dental extractions as a result of caries are unacceptable for all children. However, early removal of primary teeth in children with a cleft is particularly contraindicated because of possible space loss, especially in the upper arch, making orthodontic treatment more difficult (Fig. 4). An intact dentition will allow for the best possible results from later orthodontic intervention if required.

\section{Considerations for planning dental care}

Medical history

The child with a cleft may have an associated syndrome or sequence, such as Pierre Robin, ${ }^{9}$ or have additional medical problems. They may be under the care of a paediatrician or other specialist. An understanding of the medical condition is essential to allow for appropriate dental

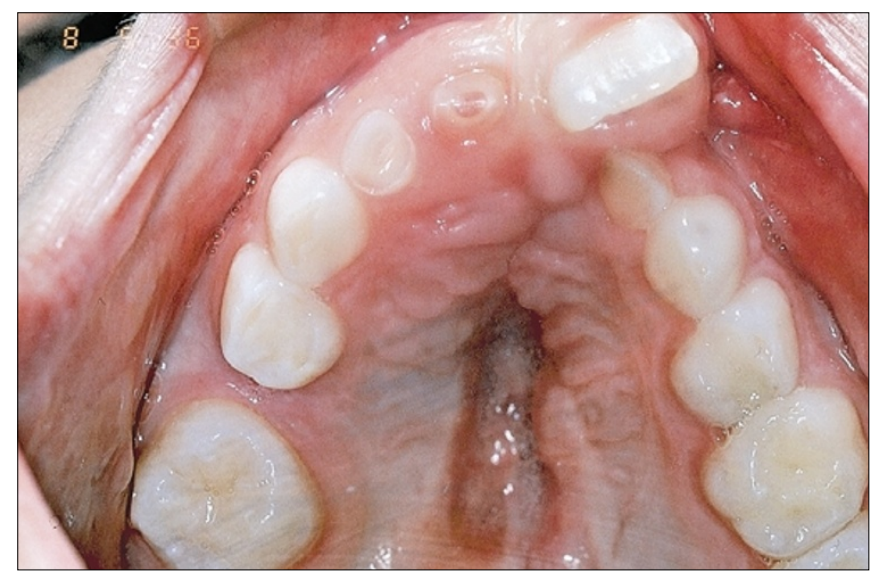


management and treatment planning. In particular, the implications of any medical conditions in relation to dental care or dental disease, for example, a congenital cardiac anomaly, should be fully discussed with the relevant specialist.

Young patients with a cleft lip and palate often have associated middle ear problems and consequent hearing difficulties. These children may have a history of frequent courses of antibiotics for repeated ear infections. They may be under the care of an ENT surgeon and require the placement of grommets under general anaesthesia. The need for general anaesthesia for surgical procedures might present an opportunity for necessary dental treatment to be carried out simultaneously. This requires good communication between the hospital and dentist providing regular care.

It is important to obtain details concerning the child's prescribed medication. The regular administration of sucrosecontaining medicines will give rise to dental caries. ${ }^{10}$ It is essential to explore the possibility of a sugar-free alternative in these cases.

\section{Social history}

An appreciation of the family situation is important to allow for the optimum delivery of dental care. Each patient and their family have their own particular needs and these gradually become apparent as a trusting relationship is built with the dentist.

Some parents feel isolated with their problem, while others cope very well. The Cleft Lip and Palate Association (CLAPA - CLAPA Head Office, 134 Buckingham Palace Road, London SW1 9SA) is a support group formed by parents of children with a cleft and professional staff caring for these patients. Contact with other parents and children in a similar situation is helpful for some families.

\section{Behaviour management}

In some cases the young patient with a repaired cleft may be shy, nervous, or have a behavioural problem. The reasons are usually multi-factorial but frequent hospital visits and previous hospitalisation may play a part. Children may also be influenced by their parents' behaviour, which is sometimes anxious and overprotective. The dentist needs patience to establish good communication, especially in the early years. Speech and hearing difficulties are a common occurrence in patients with a cleft palate. Speech development is monitored from an early age by a speech and language therapist. Problems with speech and hearing may present a possible barrier to satisfactory communication with the child.

It is important to get to know the patient as an individual and to allow time for the necessary behaviour management, acclimatisation and confidence building. However, it is equally important to get to know the parents, as gaining their trust and confidence will facilitate the provision of regular dental care.

\section{The dental examination}

The easiest way to examine a baby is with its head gently lowered onto the dentist's lap and the parent sitting facing the dentist, supporting and controlling the child's arms and legs (Fig. 5). The use of a small dental mirror (eg Busch no. 2, $18 \mathrm{~mm}$ diameter mirror [Busch \& Co, Engelskirchen, Germany; UK distributors: Glover Dental Supplies Ltd, Lancaster Road, Shrewsbury]) is helpful in tiny mouths, especially in the patient with a cleft. Particular care is needed when examining the palatal cleft area as teeth are easily missed in this region.

For the young child with a cleft lip and palate, it helps if the dentist shows the area of the cleft on the alveolus and hard palate to the parent and points out all the teeth present. Simple explanations of the variability in dental development at the site of the cleft may help to alleviate parental concerns. The number of teeth, and their eruption pattern, morphology and position can be worrying for parents. There may be missing teeth, commonly the upper primary lateral incisor (Fig. 6), or there may be supernumerary teeth present in the cleft area. Teeth in the cleft region are often crowded and rotated. They may be of poor quality with hypoplastic enamel (Fig. 6) and can therefore easily become carious. ${ }^{7}$

\section{Preventive management}

\section{Diet}

Feeding difficulties are a common problem for babies with a cleft palate ${ }^{11}$ and few mothers are successful with breast feeding. The use of feeding plates and pre-surgical orthopaedic correction plates is controversial and varies regionally between cleft teams. Specialised feeding bottles such as the Haberman feeder (Athrodax Surgical Ltd, Ross-on-Wye, Herefordshire) and Mead Johnson bottle (Mead Johnson Nutritionals, Hounslow, Middlesex) have helped to overcome some of the feeding problems. The Haberman system consists of a standard bottle with a soft variableflow teat and a pump action valve, requiring no active suction for operation. ${ }^{12}$ The Mead Johnson is a very soft bottle which can be squeezed to help the flow of milk and any standard teat can be fitted. Various
Fig. 5 Dental examination of a young child

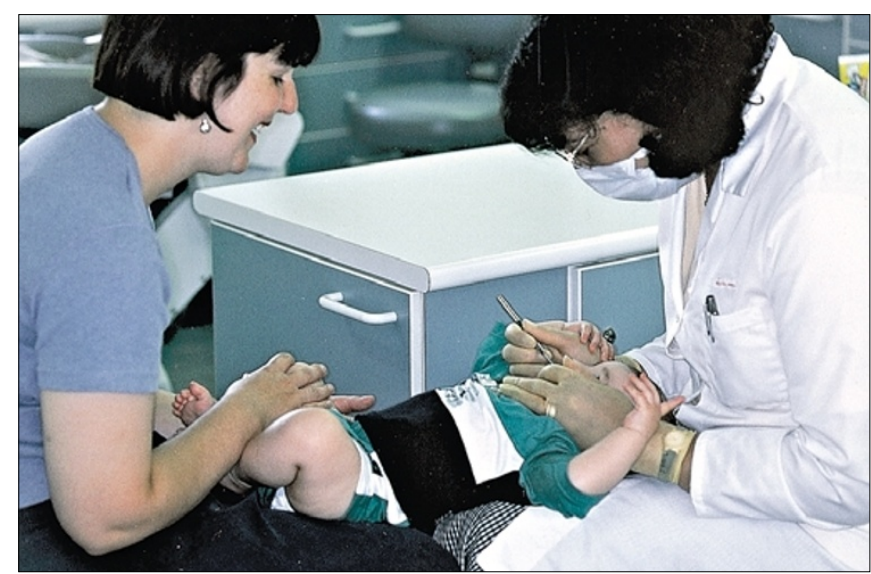


other bottles and teats are recommended by the Cleft Lip and Palate Association with the main aim of encouraging normal feeding methods whenever possible.

Parents should be recommended milk and cooled, boiled water as the only suitable dentally-safe drinks for use in a feeding bottle. They should be made aware that fruit drinks and squashes, including baby fruit juices, have an erosive potential. ${ }^{13}$ Sugar-containing and acidic drinks should be kept to a minimum and given at mealtimes only, with the introduction of a training beaker or cup from the age of 6 months. The dentist is in a position to help with advice on weaning practices. Weaning foods and drinks should be free from non-milk extrinsic sugars, as far as possible, to encourage good dietary habits for a healthy dentition. ${ }^{14}$

Parents need to appreciate the importance of good dental health before the teeth erupt. They should be given the correct advice regarding dietary control of sugar-containing food and drinks, and know how to implement it. ${ }^{15}$ They need to understand fully the relationship between the frequency of sugar in the diet and tooth decay, in simple terms. Snacks should be free from sugars, and foods containing non-milk extrinsic sugars should be kept as an occasional 'pudding' after a meal.

Babies with a cleft are usually able to cope with a dummy, although its use is best deferred until after the palate repair is fully healed. The exception to this is the baby with the Pierre Robin sequence, where the use of a dummy can help to encourage the sucking reflex. As for all babies, parents are advised that the dummy should not be dipped in any food or drink and comforters containing sweetened drinks should also be avoided, especially at bedtime. While verbal dietary advice should always be given to parents, it is useful to give them written instructions. These can be referred to at home and shown to resistant or wellmeaning family members, friends, childminders and other providers of child care.

\section{Toothbrushing}

Parents may be nervous to brush in the region of the cleft, especially following the

\section{Fig. 6 A 4-year-old child with a left unilateral cleft lip and palate. Shows missing upper left primary lateral incisor and hypoplastic upper left primary central incisor}

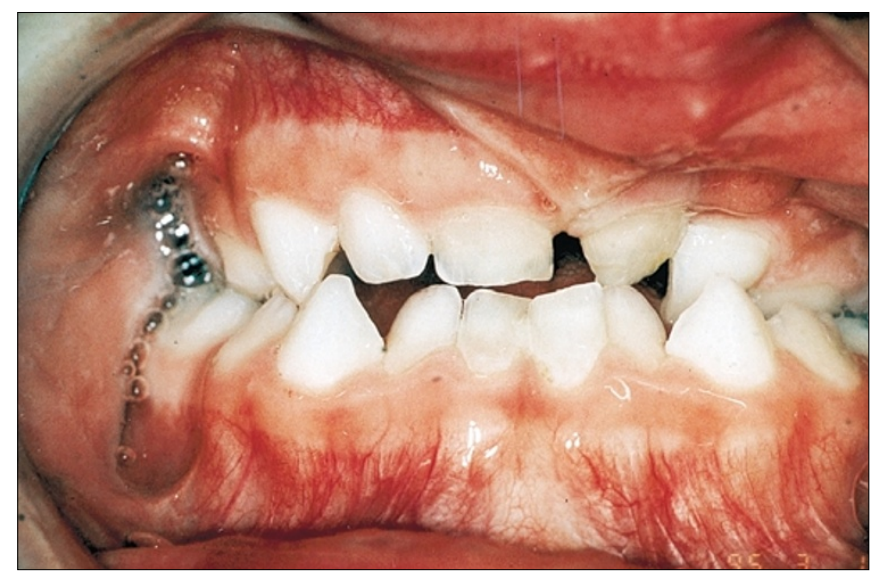

primary lip and palate surgery. They often think that bleeding from gingival inflammation is caused by damage from toothbrushing or the breakdown of the surgical repair. Parents need to understand the value of toothbrushing. They should be shown in detail how to brush the teeth and gums properly. It is important to point out the potential problem areas of plaque accumulation around the teeth in the cleft region. ${ }^{6}$ The use of the dental mirror with the child supine will aid demonstration of difficult access regions to the parent by indirect vision.

Where the upper lip has been repaired, parents should be shown how to lift it, stretching the lip carefully by sliding an index finger along the labial gingivae, without doing any damage to the scar. This helps to give them a clear view of the cleft region with good access to the crowns of the anterior teeth and the gingival margins for plaque removal. Parents should be given the opportunity to practice the toothbrushing technique in the dental surgery. Once they understand what they need to do and feel reassured that they are not causing harm to the cleft region, they can then carry out regular toothbrushing with confidence.

A small baby brush is advised as the first toothbrush. For many children with clefts, this size of brush can be used up until the eruption of the first permanent molars and beyond. A small-sized head is ideal where there is a lack of sulcus depth, or awkward tooth positions in the cleft region. An interspace brush is a useful additional aid where there is overlap and crowding of teeth, or in the case of the bilateral cleft where the upper anteriors can be very retroclined. It is especially helpful for teeth in the cleft region of the hard palate (Fig. 7).

For the toddler, parents are advised to stand or kneel behind the child when brushing, with the chin supported and head resting against the parents' chest. It may help if the child is in their baby seat or pushchair, or even lying on the carpet. Children may resist toothbrushing and confrontation situations in the bathroom should be avoided. Enlisting the help of a second person is useful on these occasions. With the child supine, one person can concentrate on the brushing with the child's head in their lap while the other person can control the legs and arms while distracting the child. Varying the time and place of toothbrushing for a brief period is another good ploy to bring in a surprise element to cope with the unco-operative child. Many parents who are keen to do their best become anxious if they have problems. Parents of children with a cleft lip and palate need extra support, encouragement and praise to persevere.

A low fluoride children's toothpaste containing no more than 600 ppm fluoride is recommended for children under 6 years of age in order to reduce the likelihood of enamel opacities in the permanent teeth. ${ }^{16}$ Children with a high risk of developing caries should use a standard toothpaste (1,000 ppm fluoride). Parents 


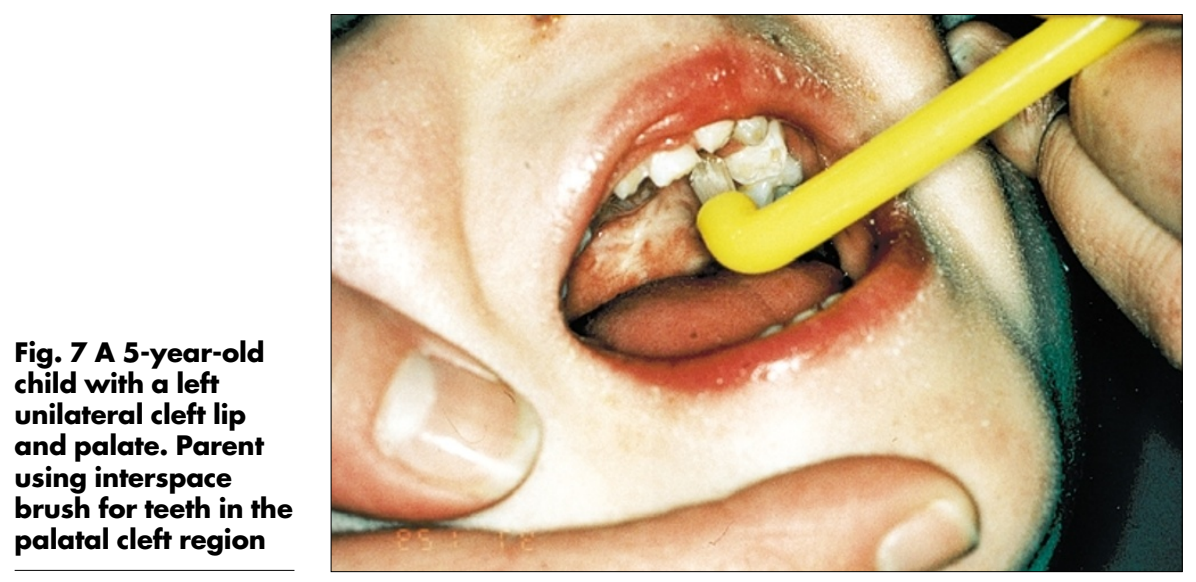

are advised to use just a trace on the brush initially, and to brush with water rather than not brushing at all if the child cannot tolerate the taste. The eventual goal is to establish a twice-daily toothbrushing regime with the recommendation of no more than a small pea-sized amount of toothpaste on the brush. Parental help and supervision continues to be important at least until 7 or 8 years of age. ${ }^{16,17}$

\section{Use of fluoride}

Fluoride supplements. The use of fluoride supplements needs to be considered and discussed with the parents as a caries-free dentition is a high priority for this group of patients. Current recommendations and dosages for fluoride dietary supplements have been published. ${ }^{17,18}$ Decisions regarding fluoride supplements will depend on various factors such as the fluoride content of the local water supply, the likelihood of compliance, the caries experience of the patient and other family members, and other factors related to the family's social circumstances.

Fluoride varnish. Regular dental check-ups should help to detect early enamel demineralisation which can be arrested by the implementation of a good preventive regime. The main preventive measures are the dietary control of sugar, thorough toothbrushing with a fluoride toothpaste and the use of fluoride supplements where indicated. In addition, the twice-yearly professional application of topical fluoride varnish is a very useful preventive measure for teeth that are at risk from caries. ${ }^{19}$ These include hypoplastic or crowded teeth in the cleft region, and any teeth which already show early signs of decalcification. Fluoride varnish should always be applied carefully, bearing in mind the high fluoride concentration of the varnish ( $5 \%$ sodium fluoride). With a co-operative child the best method of application is to apply the varnish with a brush to dried tooth surfaces. The applied varnish sets in contact with saliva.

\section{Use of personal child health record}

This is currently issued to the parents of all new-born babies in the United Kingdom. ${ }^{20}$ It contains information on the child's health, growth and development from birth and provides a helpful record book for parents and other health professionals. There is a section on dental care by the British Society of Paediatric Dentistry and the British Association for the Study of Community Dentistry, with space for the dentist to write details of dental visits. Use of this book by the child's dentist could help to reinforce the important aspects of dental care which are highlighted in the book, and improve communication between some of the health professionals providing care for the child with a cleft.

\section{Restorative care}

As for all children, the aim for the child with a cleft lip and palate is a caries-free dentition. If carious lesions have devel- oped, it is essential that they are restored as soon as possible with the most suitable material. Radiographic assessment is necessary for thorough treatment planning with regard to caries activity and progression. Bitewing radiographs should be considered once the child is able to cooperate satisfactorily (See 'Radiographic management' in Part 2).

Principles of child management, prevention of dental disease and restorative care for children have been well-documented in the dental literature and the reader is advised to consult such texts for the current definitive guidelines on these topics. $^{21-24}$

\section{Communication with the cleft team}

For the parents of babies with a cleft, the stages of cleft surgery are major 'landmarks' or 'milestones'. The dentist needs to have an understanding of the surgical procedures and their timing so that dental care can be integrated sensitively within the overall treatment plan.

Good communication between the dentist and the cleft team is essential for accurate exchange of information. It is important for the dentist to liaise with the cleft team (and vice versa) and this should be ongoing throughout the whole of the cleft management period. Two-way communication helps to achieve the most effective treatment plan for the individual. For example, the dentist needs to inform the orthodontist about any relevant dental management problems, such as a high caries rate or behavioural difficulties. Teeth with a poor long-term prognosis should be discussed in order to aid future orthodontic treatment planning. Any extractions as a result of caries should be jointly planned, especially if teeth are to be removed under general anaesthesia. A short letter or telephone call is often all that is required.

\section{Summary}

An important aim of these early visits is to deal with any worries as soon as they arise. Parents should feel able to ask questions at any time, either face-to-face or by telephone, and be made to feel that nothing is too trivial. Detailed note-taking helps to keep a record of the preventive 
advice given and any problems encountered which can be referred to at subsequent visits. Seeing the parent and child on a regular basis encourages a good relationship. Time invested at this early stage is invaluable and check-up visits at four, or six-monthly intervals, or more frequently if necessary, are advisable for careful monitoring of the child's oral health. ${ }^{25}$

Part 2, the second and final article, will deal with dental care for the patient with a cleft lip and palate from the mixed dentition stage through to adolescence and young adulthood.

1 Coupland M A, Coupland A I. Seasonality, incidence, and sex distribution of cleft lip and palate births in Trent region, 1973-1982. Cleft Palate J 1988; 25: 33-37.

2 Gregg T, Boyd D, Richardson A. The incidence of cleft lip and palate in Northern Ireland from 1980-1990. Br J Orthod 1994; 21: 387-392.

3 Albery E H, Hathorn I S, Pigott R W. Cleft lip and palate: a team approach. Bristol: Wright, 1986.

4 Shaw W C, Williams A C, Sandy J R, Devlin H B. Minimum standards for the management of cleft lip and palate: efforts to close the audit loop. Ann R Coll Surg Engl 1996; 78: 110-114.
5 Clinical Standards Advisory Group Report on Cleft Lip and/or Palate. London: The Stationery Office, 1998.

6 Bokhout B, Hofman F X W M, van Limbeek J, Kramer G J C, Prahl-Andersen B. Incidence of dental caries in the primary dentition in children with a cleft lip and/or palate. Caries Res 1997; 31: 8-12.

7 Johnsen D C, Dixon M. Dental caries of primary incisors in children with cleft lip and palate. Cleft Palate J 1984; 21: 104-109.

8 Roberts-Harry D, Sandy J R. Repair of cleft lip and palate: 1 . Surgical techniques. Dent Update 1992; 19: 418-423.

9 Sommerlad B C. Management of cleft lip and palate. Curr Paediatr 1994; 4: 189-195.

10 Roberts I F, Roberts G J. Relation between medicines sweetened with sucrose and dental disease. Br Med J 1979; 2: 14-16.

11 Trenouth M J, Campbell A N. Questionnaire evaluation of feeding methods for cleft lip and palate neonates. Int J Paediatr Dent 1996; 6: 241-244.

12 Thom A R. Modern management of the cleft lip and palate patient. Dent Update 1990; 17: 402-408.

13 Smith A J, Shaw L. Baby fruit juices and tooth erosion. Br Dent J 1987; 162: 65-67.

14 Holt R D, Moynihan P J. The weaning diet and dental health. Br Dent J 1996; 181: 254-258.

15 Health Education Authority. The scientific basis of dental health education. 4th ed. London: HEA, 1996.
16 Rock W P. Young children and fluoride toothpaste. Br Dent J 1994; 177: 17-20.

17 British Society of Paediatric Dentistry. A policy document on fluoride dietary supplements and fluoride toothpastes for children. Int J Paediatr Dent 1996; 6: 139-142.

18 A statement by the British Dental Association, the British Society of Paediatric Dentistry and the British Association for the Study of Community Dentistry. Fluoride supplement dosage. Br Dent J 1997; 182: 6-7.

19 Clark D C. A review on fluoride varnishes: an alternative topical fluoride treatment. Community Dent Oral Epidemiol 1982; 10: 117-123.

20 Goodman J R. News and views: Personal child health records. Int J Paediatr Dent 1995; 5: 278-279.

21 Andlaw R J, Rock W P. A Manual of Paediatric Dentistry. 4th ed. Edinburgh: Churchill Livingstone, 1996.

22 Curzon M E J, Roberts J F, Kennedy D B. Kennedy's Paediatric Operative Dentistry. 4th ed. Oxford: Butterworth Heinemann, 1996.

23 Welbury R. Paediatric Dentistry. 1st ed. Oxford: Oxford Univ Press, 1997.

24 Setting Standards in Dental Care for Children. Dental Profile special ed. Dental Practice Board, 1997.

25 National Clinical Guidelines: Paediatric Dentistry. Continuing Oral Care - Review and Recall: The Faculty of Dental Surgery of the Royal College of Surgeons of England, 1997.

\section{Continuing Professional Development}

The response to the first unit of CPD, Endodontics has been far greater than anticipated and unfortunately this has resulted in delays in the marking process. We hope to inform participants of their results in early January. The BDJ aplogises for any delay and would like to thank those that sent in their answers for taking part and for their patience.

Any other developments will also be announced via the website:

\section{www.bdj.co.uk/cpd}

